\begin{tabular}{|c|c|c|}
\hline & Journal Homepage: -www.journalijar.com & $\begin{array}{l}\text { INTERNATIONAL JOURNAL OF } \\
\text { ADVANCED RESEARCH (IJAR) }\end{array}$ \\
\hline ISSN NO. 2320-5407 & $\begin{array}{l}\text { Article DOI:10.21474/IJAR01/8519 } \\
\text { DOI URL: http://dx.doi.org/10.21474/IJAR01/8519 }\end{array}$ & \\
\hline
\end{tabular}

RESEARCH ARTICLE

\title{
DIAGNOSIS OF FIBROCYSTIC DISEASE OF BREAST ON ULTRASOUND.
}

\section{Samia Perwaiz Khan ${ }^{1}$ and Arwa Iqbal Hussain ${ }^{2}$.}

1. Professor \& Head Of Department Pharmacology \& Sonologist.

2. Consultant Radiologist.

\section{Manuscript Info}

\section{Manuscript History}

Received: 06 December 2018

Final Accepted: 08 January 2019

Published: February 2019

Key words:-

Ultrasound, BI-RADS, Breast Imaging

Reporting and Data System.

\section{Abstract}

Clinical examination prior to breast ultrasound include palpation of the breasts, axillae, and supra andinfraclavicular lymph nodes. This part of the examination may revealed isolated nodules in either of four quadrant of both breasts. According BI- RADs, Breast Imaging Reporting and Data System into 5 categories.Improvement in ultrasound scanning of breast for diagnosis of begin and malignant lesion by use of B-mode and Doppler ultrasound.

Methodology: Ultrasound examination was performed using XARIO, ultrasound machines,equipped with a variable-frequency linear transducer 9 to $11 \mathrm{HERTZ}$ atappropriate magnification. For detection of lesions in the lateral aspectof the breast, the patient was imaged in the supine-obliqueposition, and for other lesions, the patient was supine.Images were acquired in both radial and transverse planesand measurements were made using calipers. B-mode images were obtained in some cases to better detection of the lesion. Doppler ultrasound, was done to assess and vascularity of lesion. Ultrasound was performed byexperienced sonologist. All findings were categorized according to BI-RADS.

Results: ultrasounds of females with complaints of lump were included in study from November 2017 to November 2018 at Medicare hospital, Jinnah Medical and Dental College.Images by B-mode for imagining simple cysts, appeared anechoic with posterior enhancement and smooth borders $(n=25)$. Mostly rounded or oval in shape.Fibroadenoma appeared hypoechoic, elliptical, lying parallel to the breast planes with lateral shadowing $(n=25)$. Mostly found in inner quadrant of both breasts. No complex cyst or malignant lesion seen. Doppler ultrasound was performed to exclude any vascularity of the lesion.

\section{Conclusion:}

Ultrasound was found to be most convenient tool for assessment of breast lesions of various categories and to rule out malignancy. 


\section{Introduction:-}

The BI-RADS , Breast Imaging Reporting and Data System has been developed by the American College of Radiology (ACR) to improve communication between physicians, and to standardize mammographic reporting, terms, a report organization and a classification system. [1,2] BI-RADs is used to train radiologist regarding ultrasound breast to detect any abnormality or malignancy in breast tissue in five different categories [ 3-7].

Breast ultrasound is used inmany forms. The most common ultrasound imaging used inbreast diagnosis is B-mode ultrasonography. B-mode is the most common form of imagingfor the breast, although compound imaging and harmonicimaging are being increasingly applied to better visualizebreast lesions and to reduce image artifacts. These advances, together with the standardized parameters for solid mass features, have improved the diagnostic performance of breast ultrasound.[8-10]. Both color and power Doppler imaging have been used tocharacterize breast lesions. [11]Lee et al. reported Doppler evaluation helpful in differentiating benign andmalignant masses.[13,14]

The benign masses were twice more vascular than the surrounding tissue, whilemalignant masses were five times more vascular. Thedistribution of tumor vascularity for the twogroups was also different. Tumor vascularity wasequivalent for the core and periphery of the tumor, themalignant masses had greater vascularity per unit tissuetowards the center of the mass. [15]Improvements in image quality over the years haveexpanded the role of ultrasound in the detection anddiagnosis of breast pathology, and ultrasound is routinelyused as an adjunct to X-ray mammography.[16,17]

Aim of this study was to diagnose the lesions by b-mode according to BR1-Scan category and Doppler ultrasound to find vascularity of lesions.

\section{Methodology:-}

Ultrasound (B-mode \& Doppler) was performed using XARIO, ultrasound machines, equipped with a variablefrequency linear transducer 9 to 11 HERTZ atappropriate magnification. Patient was imaged in the supineobliqueposition.Images were acquired in both anterio-posterior and longitudinal planesand measurements were made using calipers by B-mode for imagining all four quadrants. Doppler ultrasound was performed to exclude any vascularity of the lesion.

\section{Results:-}

Total eightyultrasounds of females were included in study during November 2017 to November 2018 from Medicare hospital, Jinnah Medical and Dental College.Images were acquired in both anterio-posterior and longitudinal planesand measurements were made using calipers by B-mode for imagining simple cysts, appeared anechoic with posterior enhancement and smooth borders(fig.1).Mostly rounded or oval in shape. Fibroadenoma appeared hypoechoic, elliptical, lying parallel to the breast planes with lateral shadowing. Mostly found in inner quadrant of both breasts.No complex cyst or malignant lesion seen.( table .1)

Doppler ultrasound was performed to exclude any vascularity of the lesion. No flow was seen in small fibroadenomas. However minimal flow seen in giant fibroadenomas with high resistive index.

Table 1:-Ultrasound finding in female patients, categorized according to BI- RADS.

\begin{tabular}{|c|c|c|c|}
\hline S.No. & Ultrasound image & BI-RADS & No. of patients \\
\hline 1. & Ultrasound image of normal breast tissue & Category-1 & 30 \\
\hline 3. & $\begin{array}{l}\text { Breast ultrasound image of a simple cyst, showing ovalshape, smooth } \\
\text { margins, anechoic content and posterior enhancement. }\end{array}$ & Category-2 & 25 \\
\hline 4. & $\begin{array}{l}\text { Breast ultrasound image of a solid lesion, showinglobulated shape, } \\
\text { smooth margins, homogeneous hypoechoicmatrix, parallel } \\
\text { orientation and slight posterior enhancement: } \\
\text { BI-RADS }\end{array}$ & Category-2 & 25 \\
\hline 5. & $\begin{array}{l}\text { Breast ultrasound image of a hypoechoic lesion, showingthe round } \\
\text { shape, distinct, smooth margin, indifferentorientationand mixed } \\
\text { posterior shadowing characteristic of a complex cyst. }\end{array}$ & Category-3 & $\mathbf{0}$ \\
\hline 6. & Breast ultrasound image of a solid hypoechoic lesion, & Category- & $\mathbf{0}$ \\
\hline
\end{tabular}




\begin{tabular}{|l|l|l|l|}
\hline & $\begin{array}{l}\text { showing the polymorphic shape, indistinct margin with some } \\
\text { spiculae, uncertain orientation, heterogeneous matrix andindifferent } \\
\text { echo pattern suspicious for malignancy. }\end{array}$ & $4 / 5$ & \\
\hline
\end{tabular}

Fig 1 :-B-mode ultrasound breast showing simple cysts.
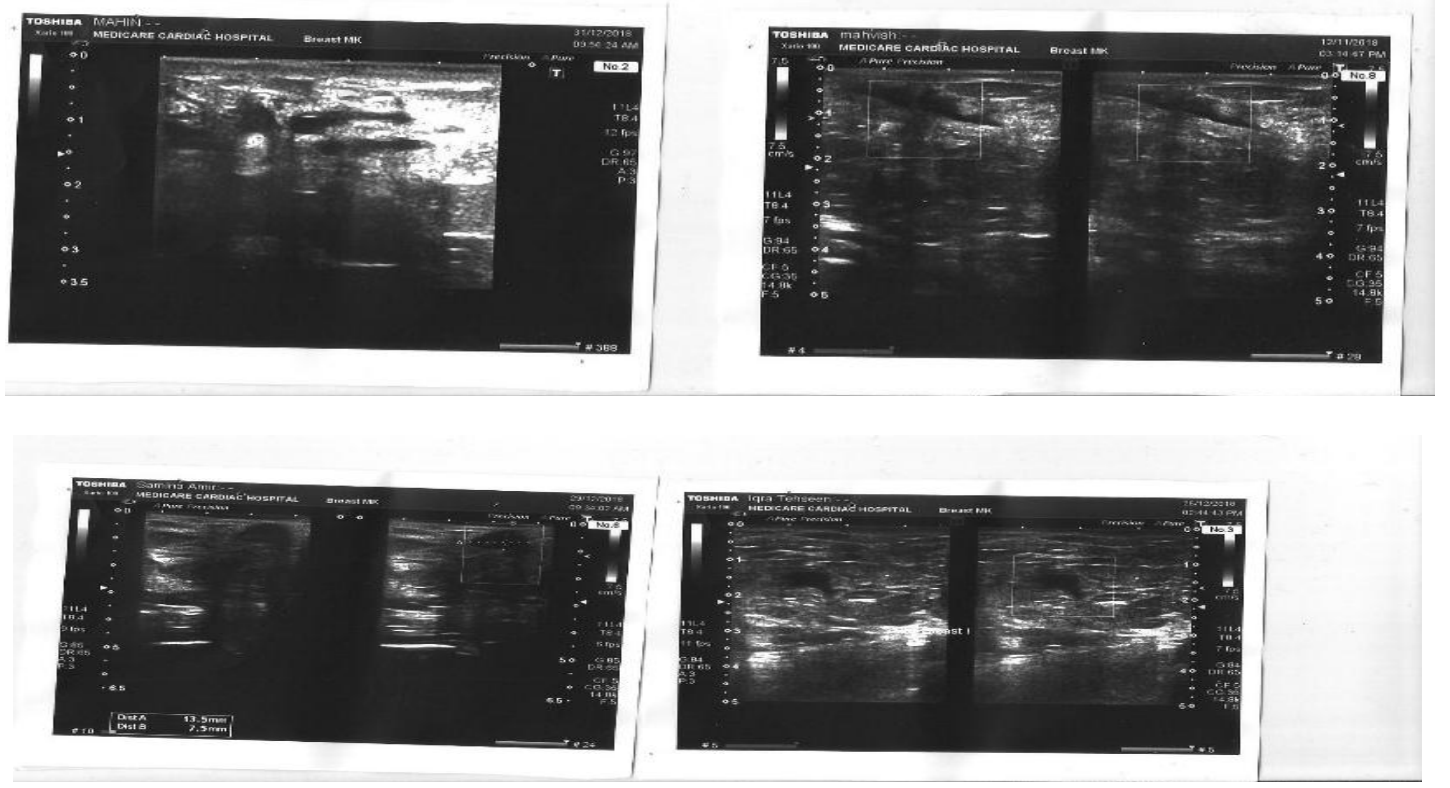

\section{Discussion:-}

In study conducted in Radiology Department, Medicare Hospital Karachi most frequent finding simple cyst with posterior enhancement categories $(1,2,3)$ were frequent finding but no malignant reported during this study. Use of B-mode were beneficial in investigation of type of lesion. Doppler was performed to rule out vascularity of lesion.

Combined use of color Doppler and SE could improve the diagnostic value of B-mode US in distinguishing benign from malignant non-mass breast lesions and the specificity of making the decision for biopsy of non-mass breast lesions.[12-14]Elastography and color Doppler US are imaging techniques for the diagnosis of breast lesions at Bmode US. Elastography and color Doppler US cannot reduce the number of recalls at screening US for potentially abnormal findings for which additional imaging is needed; however, it may change the management for lesions detected at screening US.[15-18]Addition of elastography and color Doppler US to B-mode US can increase the Positive Predictive Value of screening US in women with dense breasts while reducing the number of false-positive findings without missing cancers.[10].US as an adjunct to mammography canincrease the sensitivity and detection rate of early cancers while reducing interval cancers in women with dense [11-16]Several approaches that are currently being investigated to further improve performance include: (a) computer-aided-diagnosis; (b) the assessment of tumor vascularity and tumor blood flow with Doppler ultrasound and contrast agents; and (c) tissue elasticity imaging. Ultrasound will have a greater role in differentiating benign from malignant masses and in the diagnosis of breast cancer by elastography.[18] Breast ultrasound is routinely used for differentiating cysts and solid nodules with high specificity. In combination with mammography, ultrasound is used to characterize solid masses as benign or malignant. There is growing interest in using Doppler ultrasound and contrast agents for measuring tumor blood flow and for imaging tumor vascularity.[19-21]

\section{Conclusion:-}

Ultrasound examination is highly beneficial, convenient and non-invasive technique in categorizing the changes , which could be either benign or malignant finding for the diagnosis of breast lesions. 


\section{Reference:-}

1. American College of Radiology. BI-RADS: ultrasound. In:Breast Imaging Reporting and Data System: BIRADS Atlas $\left(4^{\text {th }}\right.$ edn $)$. American College of Radiology: Reston, VA,2003.

2. TimmersJMH,vanTinteren JH, Visser O, Verbeek A.L.M, den HeetenGJ,andBroeders MJM . The Breast Imaging Reporting and Data System (BI-RADS) in the Dutch breast cancer screening programme: its role as an assessment and stratification tool.EurRadiol. 2012 Aug; 22(8): 1717-1723.

3. American College of Radiology (2003) ACR BI-RADS®-Mammography: Breast Imaging Reporting and Data System, Breast Imaging Atlas, vol 4. ACR, Preston.

4. Timmers JM, van Doorne-Nagtegaal HJ, Verbeek AL, den Heeten GJ, Broeders MJ (2011) A dedicated BIRADS training programme: effect on the inter-observer variation among screening radiologists. Eur J Radiol (in press) [PubMed]

5. Lehman CD, Miller L, Rutter CM, Tsu V. Effect of training with the American College of Radiology Breast Imaging Reporting and Data System lexicon on mammographic interpretation skills in developing countries. AcadRadiol. 2001;8:647-650. doi: 10.1016/S1076-6332(03)80690-6.

6. Lehman C, Holt S, Peacock S, White E, Urban N. Use of the American College of Radiology BI-RADS guidelines by community radiologists: concordance of assessments and recommendations assigned to screening mammograms. AJR Am J Roentgenol. 2002;179:15-20. [PubMed]

7. Lehman C, Holt S, Peacock S, White E, Urban N. Use of the American College of Radiology BI-RADS guidelines by community radiologists: concordance of assessments and recommendations assigned to screening mammograms. AJR Am J Roentgenol. 2002;179:15-20. [PubMed]

8. Kremkau FW. Diagnostic ultrasound: principles and instruments.5th ed. Philadelphia: WB Saunders; 1984.

9. Hedrick WR, Hykes DL, Starchman DE. Ultrasound physics and instrumentation. 3rd ed. St Louis: Mosby; 1995.

10. Zagzebski JA. Essentials of ultrasound physics. St Louis: Mosby; 1996.

11. li l, zhou x, hao s, yao j, zhong w et al. b-mode ultrasound combined with color doppler and strain elastography in the diagnosis of non-mass breast lesions: a prospective study. ultrasound in medicine and biology. november 2017volume 43, issue 11, pages 2582-2590

12. Evaluation of screening Us-detected Breast Masses by combined Use of elastography and color Doppler Uswith B-Mode Us in Women with dense Breasts: A Multicenter Prospective Study.

13. Sehgal CM, Arger PH, Rowling SE. Quantitative vascularity ofbreast masses by Doppler imaging: regional variations anddiagnostic implications. J Ultrasound Med 2000;19:427-40.

14. Lee SW, Choi HY, Baek SY, Lim SM. Role of color and powerDoppler imaging in differentiating between malignant andbenign solid breast masses. J Clin Ultrasound 2002;30:459-64.

15. Corsetti V, Houssami N, Ghirardi M, et al. Evidence of the effect of adjunct ultrasound screening in women with ammography-negative dense breasts: interval breast cancers at 1 year follow-up. Eur $\mathrm{J}$ Cancer 2011;47(7):1021-1026.

16. Hooley RJ, Greenberg KL, Stackhouse RM,Geisel JL, Butler RS, Philpotts LE. Screening US in patients with mammographically dense breasts: initial experience with Connecticut Public Act 09-41. Radiology 2012;265(1):59-69.

17. Ohuchi N, Suzuki A, Sobue T, et al. Sensitivity and specificity of mammography andadjunctive ultrasonography to screen for breast cancer in the Japan Strategic Anti-cancer Randomized Trial (J-START): a ran-domised controlled trial. Lancet 2016;387.(10016):341-348

18. SehgalCM , Weinstein SP, Arger PH, Conant EF. A Review of Breast Ultrasound.J Mammary Gland BiolNeoplasia (2006) 11: 113-123.

19. CM Sehgal, PH Arger,et.alQuantitative analysis of color and power Doppler $122 \mathrm{~J}$ Mammary Gland BiolNeoplasia.J Ultrasound Med $\bullet 2006$

20. CM Sehgal,Weinstein SM et al.Diagnostic performance of contrast-enhanced ultrasound and enhanced magnetic resonance for breast nodules.2018, Journal of biomedical research.DOI:10.7555/JBR.32.20180015

21. Tan SM, Teh HS, Mancer JF, PohWTImproving B mode ultrasound evaluation of breast lesions with real-time ultrasound elastography--a clinical approach. Breast. 2008 Jun;17(3):252-7. Epub 2007 Nov 28. 